\title{
Mechanisms of cast structure and stressed state formation in Hadfield steel
}

\author{
*Dmitri Gorlenko, Konstantin Vdovin and Nikolay Feoktistov \\ Nosov Magnitogorsk State Technical University, Magnitogorsk, Russia
}

\begin{abstract}
The paper describes the investigation of mechanisms of cast structure formation in Hadfield steel depending on the changes in the cooling rate of a casting in the following two temperature ranges: crystallization temperature $\left(1,200-1,390{ }^{\circ} \mathrm{C}\right)$ and the temperature of excessive phase separation $\left(560-790{ }^{\circ} \mathrm{C}\right)$. Changes in the cooling rate of the crystallization temperature range from 1.1 to $25.0^{\circ} \mathrm{C} \cdot \mathrm{s}^{-1}$ result in the reduction of the average size of austenite grains from 266 to $131 \mu \mathrm{m}$. At the same time, the magnitude of developing shrinkage stresses changes from +195 to $0 \mathrm{MPa}$. When the cooling rate is higher than $16^{\circ} \mathrm{C} \cdot \mathrm{s}^{-1}$, no shrinkage stresses are formed in the casting. Changes in the cooling rate of the casting in the temperature range of the excessive phase separation influence the number of phases, their morphology and chemical composition, the values of phase stresses, and the possibility of martensitic transformation. Changing in the cooling rate from 0.24 to $5.46{ }^{\circ} \mathrm{C} \cdot \mathrm{s}^{-1}$ results in the decrease of the amount of the excessive phase from $14.8 \%$ to $2.1 \%$, which is composed of eutectic and carbides depending on the cooling rate, their quantitative ratio and morphology change. Such changes in the microstructure are reflected on the changes of value of developing phase stresses. When the cooling rate is $0.24^{\circ} \mathrm{C} \cdot \mathrm{s}^{-1}$, it is +100 $\mathrm{MPa}$, while the increase of the cooling rate to $1.4^{\circ} \mathrm{C} \cdot \mathrm{s}^{-1}$ results in the decrease of tensile stresses to $0 \mathrm{MPa}$ and their qualitative stresses change to compressive ones. Further increase of the cooling rate results in the increase of the value of compressive stresses. When the cooling rate is $5.5^{\circ} \mathrm{C} \cdot \mathrm{s}^{-1}$, their value reaches $-92 \mathrm{MPa}$. Martensite forming in the structure of Hadfield steel is possible if the cooling rate of the casting in the range of excessive phase separation is less than $0.25^{\circ} \mathrm{C} \cdot \mathrm{s}^{-1}$.
\end{abstract}

Key words: Hadfield steel; crystallization, austenite; excessive phase; stress

CLC numbers: TG142.33 Document code: A Article ID: 1672-6421(2016)06-433-10

$\mathrm{H}$ adfield steel is widely used to manufacture various parts for mining, machine-building, metallurgy, railway and other industries. Wide application of this steel can be explained by a unique set of performance characteristics including improved wear resistance under loads ${ }^{[1-4]}$.

In spite of the fact that this steel has been used for quite a long time, in recent decades it has been attracting considerable interest of scientists in different countries ${ }^{[5]}$. Most investigations are aimed at improving its performance characteristics. This can be achieved by means of surface hardening ${ }^{[6-9]}$, alloying ${ }^{[10-19]}$ and decreasing in the content of detrimental impurities ${ }^{[20,21]}$. Another way to improve the properties of this manganese steel is to investigate

\section{*Dmitri Gorlenko}

Male, born in 1986, Assistant of Department Foundry and Materials, Nosov Magnitogorsk State Technical University, Magnitogorsk, Russia, Ph.D. (Engineering). Research interests: material science and foundry. He currently published more than 20 technical papers in journals of different levels.

E-mail: gorldima@yandex.ru its deformation mechanism as well as the influence of various factors on this mechanism ${ }^{[22-36]}$. There are a number of papers concerned with the investigation of the microstructure and properties of Hadfield steel in the as-cast and the heat-treated states ${ }^{[37-41]}$.

The literature review shows that the performance characteristics of steel are influenced by its parameters, such as its microstructure, chemical composition (including content of certain structural components) and the stressed state. However, these relationships cannot be used in the process of production of specific items as the research was carried out using model homogenized alloys, and the cooling rate in the process of structure forming was not taken into account. At the same time, the wide range of products from this steel includes castings weighing from one to several hundred kilograms. This influences cooling rates during and after crystallization. Further, it is reflected in the changes of qualitative and quantitative characteristics of their cast structure. The cast structure, in its turn, is essential, and its relationships are inherited even after heat treatment.

Received: 2016-09-30; Accepted: 2016-11-12 
In order to predict the performance characteristics of castings on the basis of the earlier research works, it is necessary to carry out a number of further investigations. In particular, it is necessary to study the influence of the cooling rate on the structure of the as-cast Hadfield steel. This relationship will provide the dependence between computer simulation of the crystallization process and the performance characteristics inherent to a certain microstructure.

The subject of this research work is the influence of the cooling rate during crystallization and after its completion on the cast structure of Hadfield steel.

\section{Materials and experimental methods}

Research was carried out using samples of Hadfield steel cooled at different cooling rates. The chemical composition of the alloy under study is given in Table 1 .

Table 1: Chemical composition of steel under study (wt.\%)

$\begin{array}{cccccccc}\mathbf{C} & \mathbf{S i} & \mathrm{Mn} & \mathbf{S} & \mathbf{P} & \mathbf{C r} & \mathrm{Ni} & \mathrm{Al} \\ 1.2 & 0.9 & 12.3 & 0.024 & 0.033 & 0.8 & 0.12 & 0.06\end{array}$

Castings of $50 \times 50 \times 15 \mathrm{~mm}$ in size were used as samples. The rate of cooling was changed by means of altering the material and temperature of the preliminary heated casting mold. A tungsten-rhenium thermocouple (Fig. 1) was used to measure the temperature in real-time mode. The measurement results were recorded and processed using a personal computer.

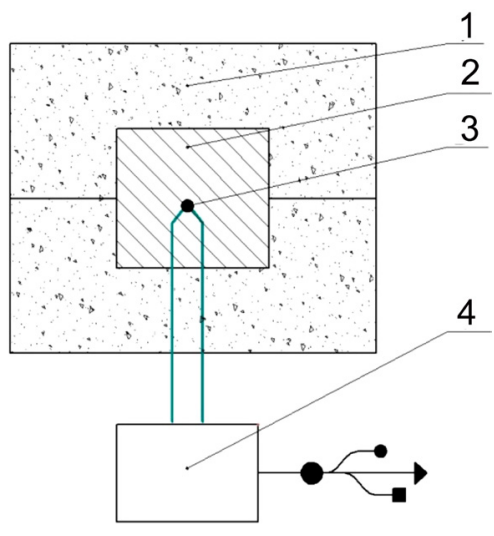

Fig. 1: General layout of a thermocouple for measuring the temperature of a casting: 1 - casting mold; 2 - casting; 3 - thermocouple; 4 - analog-to-digital converter

To determine the microstructure, a mixture of concentrated nitric acid (65wt.\%) and concentrated chlorhydric acid (35wt.\%) was used as an etching agent.

A Meiji Techno optical microscope using the computer image analysis program Thixomet PRO ${ }^{[42]}$ and a JEOL JSM6490 LV scanning electron microscope with energy dispersive
X-ray spectroscopy (EDX) INCA Energy attachment were used to determine the qualitative and quantitative characteristics of the microstructure and the amount of the excessive phase. The energy dispersive X-ray analysis of austenite was carried out in 36 points on each sample, after which the value was averaged. The chemistry of the excessive phase (eutectic and secondary carbides) was determined by several points.

The X-ray crystal structure analysis was carried out on a SHIMADZU XRD 7000 X-ray diffractometer using emission of the chrome anode $\left(\mathrm{Cr}_{\mathrm{K} \beta}\right)$. Analysis of residual stresses was carried out along the line (311) of $\gamma$-phase (double angle of diffraction $2 \theta \approx 149.6^{\circ}$ ).

The value of macrostresses was calculated according to the following formula:

$$
\sigma_{\varphi}=\frac{E \cdot \operatorname{ctg} \theta_{0}\left(2 \theta_{0}-2 \theta_{\psi}\right)}{2(1+\mu) \cdot \sin ^{2} \psi}
$$

where $2 \theta_{0}$ is the observed value of Bragg angle at $\psi=0$, rad; $2 \theta_{\psi}$ is Bragg angle during inclined imaging at an angle $\psi$, rad; $\mu$ is Poisson's constant; $E$ is the elasticity modulus (Young's modulus).

The following values of $\psi$ angle were used: $0^{\circ}, 5^{\circ}, 10^{\circ}, 15^{\circ}$, $20^{\circ}, 25^{\circ}, 30^{\circ}, 35^{\circ}, 40^{\circ}, 45^{\circ}$.

Electrolytic polishing installation Struers LectroPol-5 was used to prepare specimens, to relieve the stresses caused by the mechanical processing of specimens.

Computer simulation of the alloy crystallization process and the calculation of shrinkage stresses were carried out using the LWMFlow 4.2r2 software application and the finite-difference method.

\section{Results}

\subsection{Mechanisms of cast microstructure forming}

The austenite grain size examination was carried out using cast specimens of Hadfield steel cooled in the crystallization temperature range from $1,200-1,390{ }^{\circ} \mathrm{C}$ with the cooling rates from 1.1 to $25.0^{\circ} \mathrm{C} \cdot \mathrm{s}^{-1}$ (including cooling rates of $1.9,3.7,4.5$, $\left.8.9^{\circ} \mathrm{C} \cdot \mathrm{s}^{-1}\right)$. The microstructures of specimens cooled to room temperature are given in Fig. 2.

The analysis of the specimen microstructure resulted in the calculated relationship between the average austenite grain size of the steel under study and the cooling rate in the crystallization temperature range (Fig. 3a). This relationship shows that the most intensive grain refining (by more than $100 \mu \mathrm{m}$ ) takes place when the cooling rate increases to $10.0^{\circ} \mathrm{C} \cdot \mathrm{s}^{-1}$. Further change of the cooling rate does not have significant influence on structure refining. When the cooling rate increases by 2.5 times (to 25.0 $\left.{ }^{\circ} \mathrm{C} \cdot \mathrm{s}^{-1}\right)$, grain size is reduced by $30 \mu \mathrm{m}$.

In addition to the average grain size, the influence of the cooling rate on the nonhomogeneity of the grain structure was investigated in the examined temperature range. The most homogeneous structure is formed when the cooling rate is 8.9 ${ }^{\circ} \mathrm{C} \cdot \mathrm{s}^{-1}$. Decrease and increase of this value result in reduction 

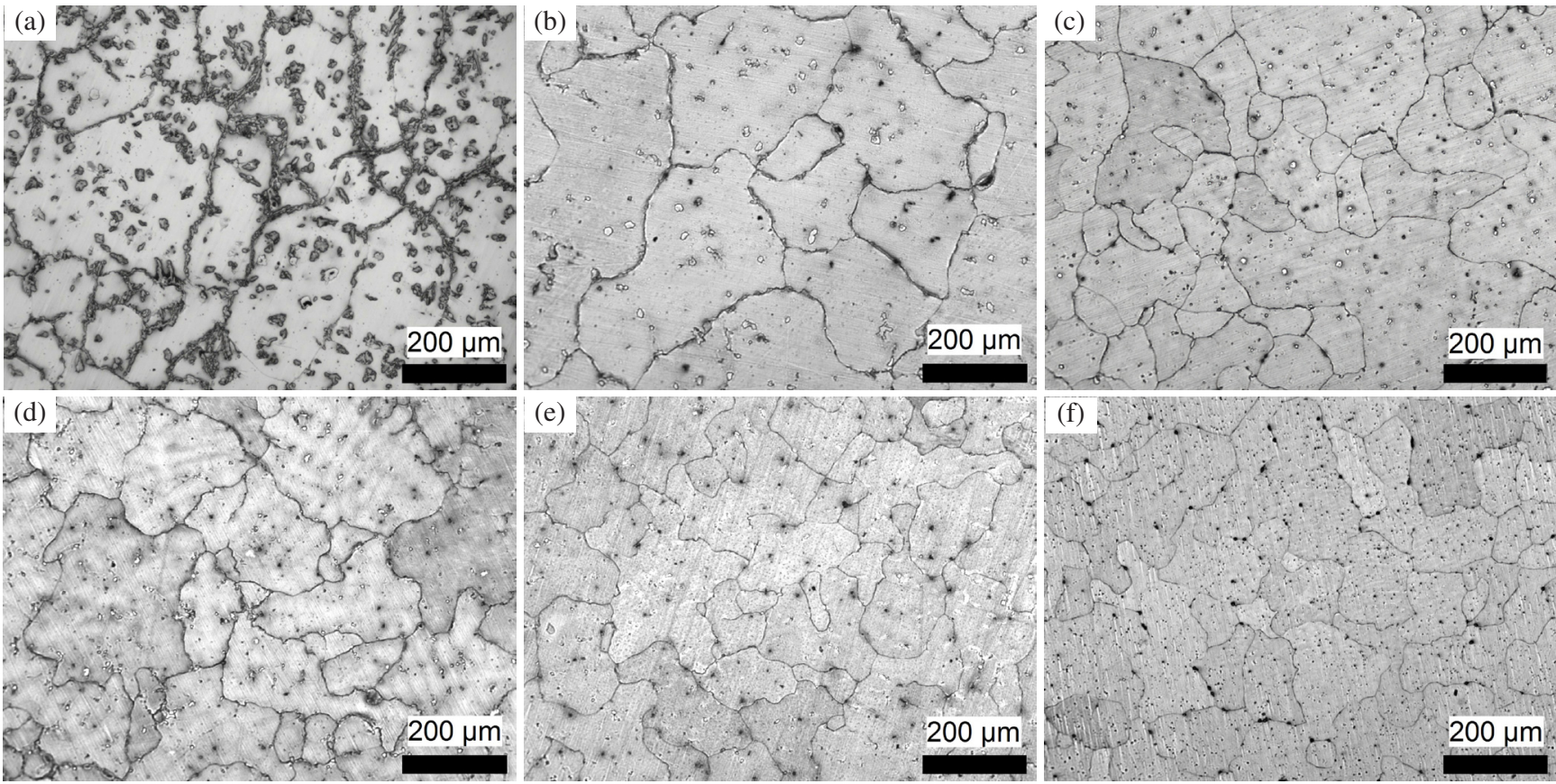

Fig. 2: Microstructure of Hadfield steel cooled in the crystallization temperature range with different cooling rates: $\mathrm{a}-1.1^{\circ} \mathrm{C} \cdot \mathrm{s}^{-1} ; \mathrm{b}-1.9^{\circ} \mathrm{C} \cdot \mathrm{s}^{-1} ; \mathrm{c}-3.7^{\circ} \mathrm{C} \cdot \mathrm{s}^{-1} ; \mathrm{d}-4.5^{\circ} \mathrm{C} \cdot \mathrm{s}^{-1} ; \mathrm{e}-8.9^{\circ} \mathrm{C} \cdot \mathrm{s}^{-1} ; \mathrm{f}-25.0^{\circ} \mathrm{C} \cdot \mathrm{s}^{-1}$
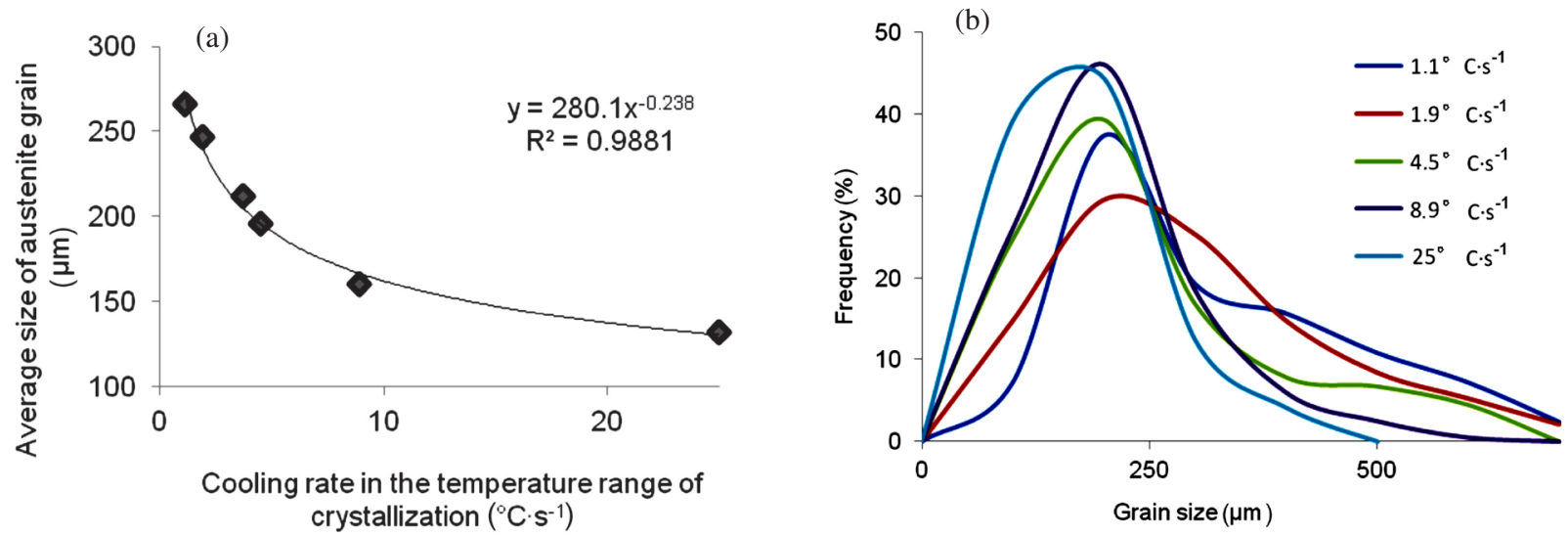

Fig. 3: Microstructure parameters of cast Hadfield steel: a - relationship between average grain size and cooling rate in the crystallization temperature range; $b$ - distribution graph of grain size in the structure formed at some cooling rates in crystallization temperature range

of the grain homogeneity, what can be seen in the graphs of frequency distribution (Fig. 3b).

Hadfield steel in the as-cast state is not single-phase. After crystallization completion, the process of cooling the crystallized casting begins, at the same time, the thermal conductivity of the alloy and its cooling rate decrease. This contributes to excessive phase separation from the oversaturated solution in a certain temperature range. Depending on the cooling rate, this temperature range is $560-790{ }^{\circ} \mathrm{C}$. The cooling rate of the same castings in this temperature range changes from 0.24 to $5.46{ }^{\circ} \mathrm{C} \cdot \mathrm{s}^{-1}$ (including $0.35 ; 0.4 ; 1.0 ; 1.8^{\circ} \mathrm{C} \cdot \mathrm{s}^{-1}$ ) respectively. Comparison of cooling rate values of a casting in different temperature ranges (crystallization and excessive phase separation) shows that the difference can be up to 4.6 times and the relation between them is linear (Fig. 4).

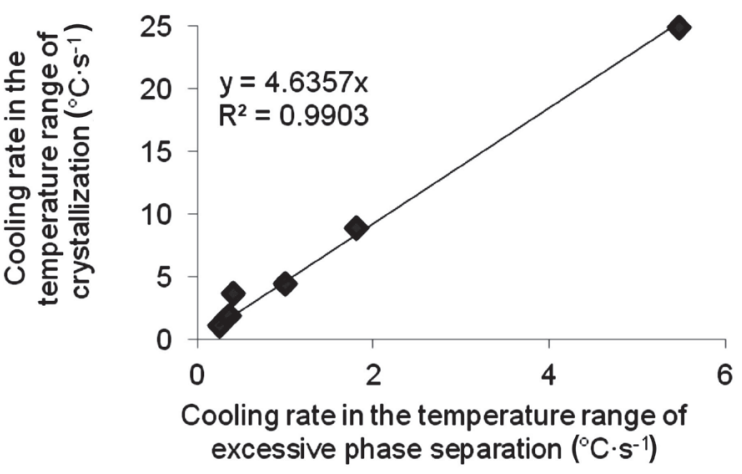

Fig. 4: Dependence of cooling rate of a casting in different temperature ranges 
The increase in the cooling rate contributes to the decrease of the excessive phase separation interval. This results in the decrease of the total amount of the excessive phase in the structure of the as-cast Hadfield steel from $14.8 \%$ to $2.1 \%$ (Fig. 5).

The obtained relationship shows that the most intensive reduction of the amount of the secondary phase takes place when the cooling rate increases from 0.24 to $1.0^{\circ} \mathrm{C} \cdot \mathrm{s}^{-1}$.

Changes of the cooling rate influence both the quantitative characteristics of the excessive phase, its morphology and chemical composition. Regardless of the cooling rate, the excessive phase is separated along the boundaries and in the austenite grains themselves.

When cooling rates are low $\left(0.24^{\circ} \mathrm{C} \cdot \mathrm{s}^{-1}\right)$, the excessive phase consists of linked fragments and forms a continuous net at the grain boundaries having a thickness of about 5-30 $\mu \mathrm{m}$ (Fig. 6). It is essentially eutectic with phosphor content within $4.7 \%-$ $6.3 \%$. Eutectic separation occurs at the constant temperature of $1,145{ }^{\circ} \mathrm{C}$, corresponding to the flat section on the cooling curve. It has a finely-dispersed lamellar structure with a carbide platelet thickness of $0.1 \mu \mathrm{m}$, and the dimensional orientation of these platelets is quite irregular. Layers of austenite from 0.03 to $0.07 \mu \mathrm{m}$ in thickness are located between the carbide platelets. Besides iron, the chemical composition of the eutectic includes manganese and carbon as well as small amounts of chrome and

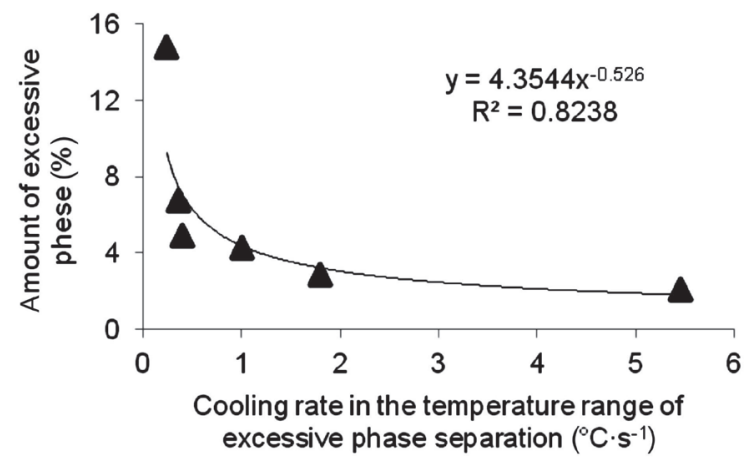

Fig. 5: Relationship between the amount of excessive phase and cooling rate of a casting in the interval of excessive phase separation

silicon. The iron-manganese ratio is $\mathrm{Fe} / \mathrm{Mn}=3.2$, which means that manganese content is very high. Such morphology and chemical composition are true for the excessive phase formed both along the grain boundaries and inside the grains.

The content of the main alloying elements in austenite is:

$\mathrm{Mn}=9.3 \mathrm{wt} . \%, \mathrm{Cr}=0.7 \mathrm{wt} . \%, \mathrm{Si}=1.0 \mathrm{wt} . \%$.

The increase of the cooling rate to $0.35{ }^{\circ} \mathrm{C} \cdot \mathrm{s}^{-1}$ leads to changes of the size and morphology of the excessive phase. The thickness of the excessive component is about 3-8 $\mu \mathrm{m}$ (Fig. 7).

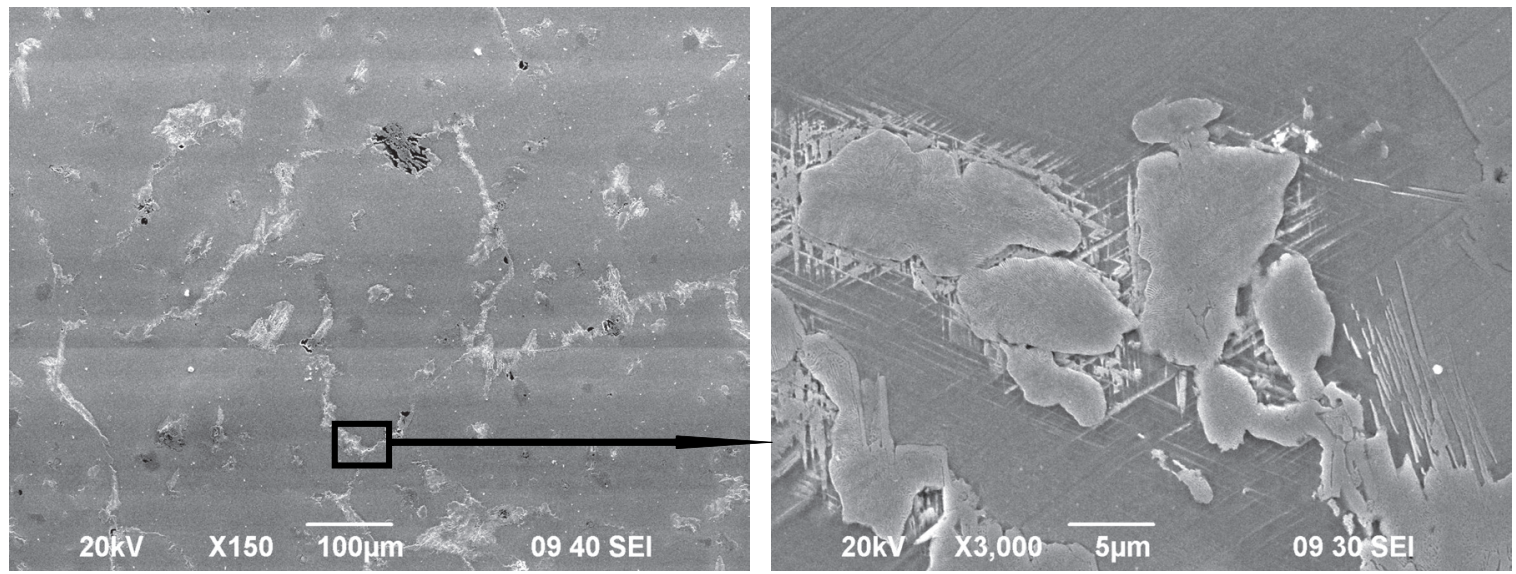

Fig. 6: Microstructure of Hadfield steel cooled in the temperature range of excessive phase separation with a cooling rate of $0.24{ }^{\circ} \mathrm{C} \cdot \mathrm{s}^{-1}$

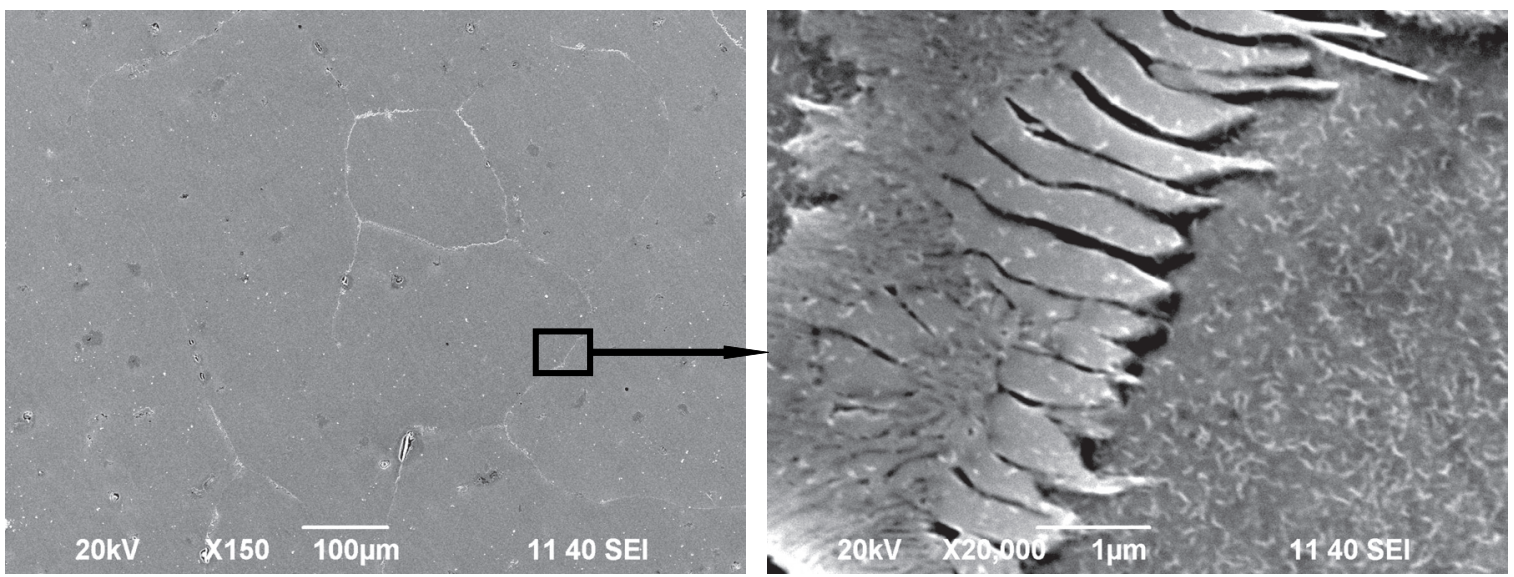

Fig. 7: Microstructure of Hadfield steel cooled in the temperature range of excessive phase separation with a cooling rate of $0.35^{\circ} \mathrm{C} \cdot \mathrm{s}^{-1}$ 
It is formed partially from lamellar eutectic, and, partially from carbide with a coherent boundary between them. At the same time, the carbide share of the excessive phase has a pronounced columnwise structure. This combined morphology is caused by the increase in the cooling rate and the hindered diffusion of phosphorus. In carbides, no phosphorus is found. The Fe/ Mn ratio increases to 3.5-3.7, showing reduction of manganese content in carbides as compared with the eutectic. In the eutectic, this ratio remains at the level of $\mathrm{Fe} / \mathrm{Mn}=3.3-3.5$. This results in the increase of manganese content in austenite to $9.5 \%$. Chrome and silicon contents remain equal to $0.7 \%$ and $1.0 \%$, respectively.

When the cooling rate increases to $0.4{ }^{\circ} \mathrm{C} \cdot \mathrm{s}^{-1}$, the thickness of the excessive phase decreases to about $1-3 \mu \mathrm{m}$. Its thickness becomes more uniform along its length and the columnwise morphology of carbides is replaced by Widmannstatten pattern. The excessive phase with the mixed morphology of thin- lamellar eutectic and carbide remains only on the boundary of three grains (Fig. 8). The Fe/Mn ratio $=4.0-4.3$, which means that the manganese content in the excessive phase continues to decrease. At the same time, its content in austenite increases to $9.8 \%$. The chrome and silicon contents in austenite also increase to $0.8 \%$ and $1.2 \%$, respectively.

When the cooling rate in the temperature range of excessive phase separation increases to $1.0^{\circ} \mathrm{C} \cdot \mathrm{s}^{-1}$, the processes, which started at lower cooling rates, continue. The thickness of the excessive phase decreases to about $0.2-0.4 \mu \mathrm{m}$ (Fig. 9), while the $\mathrm{Fe} / \mathrm{Mn}$ ratio increases to 4.7-5.1. The excessive phase with the combined morphology can also be observed on the boundary of three grains. However, when the cooling rate increases, the degree of dispersion of the lamellar part decreases and it acquires a pronounced columnwise structure. Manganese and chrome contents in austenite increase to $10 . \%$ and $0.9 \%$, respectively. Silicon content decreases to $0.9 \%$.
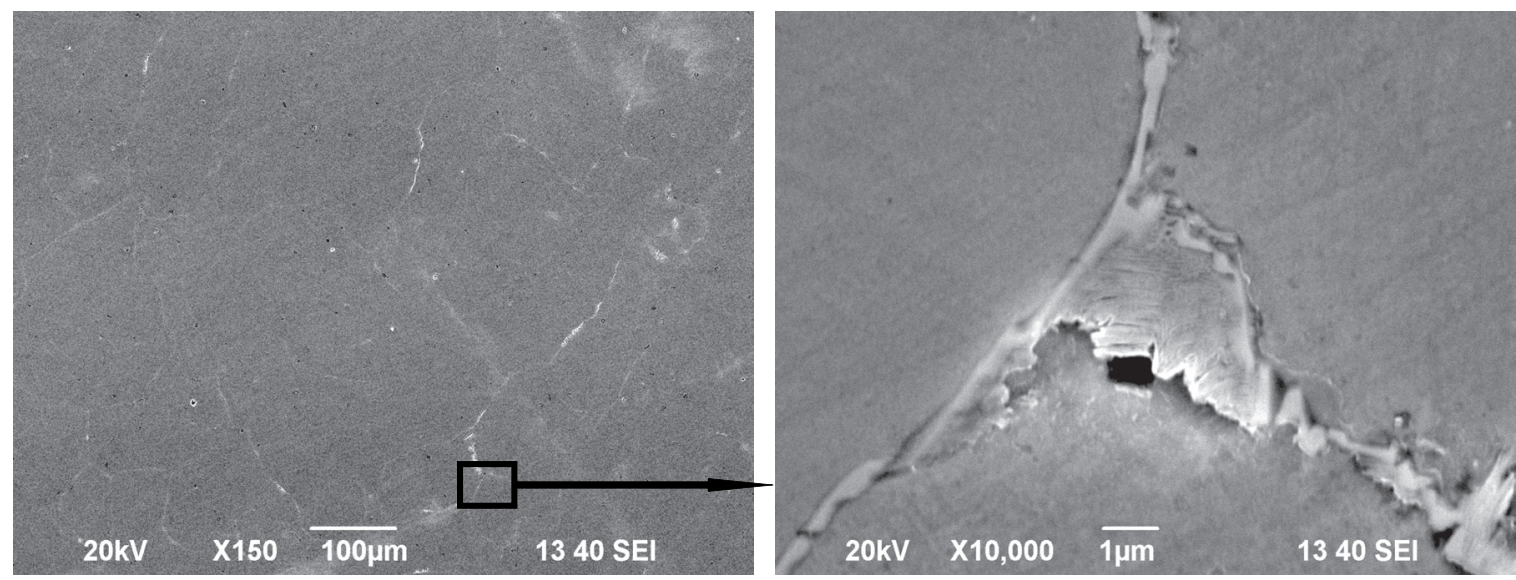

Fig. 8: Microstructure of Hadfield steel cooled in the temperature range of excessive phase separation with the cooling rate of $0.4^{\circ} \mathrm{C} \cdot \mathrm{s}^{-1}$
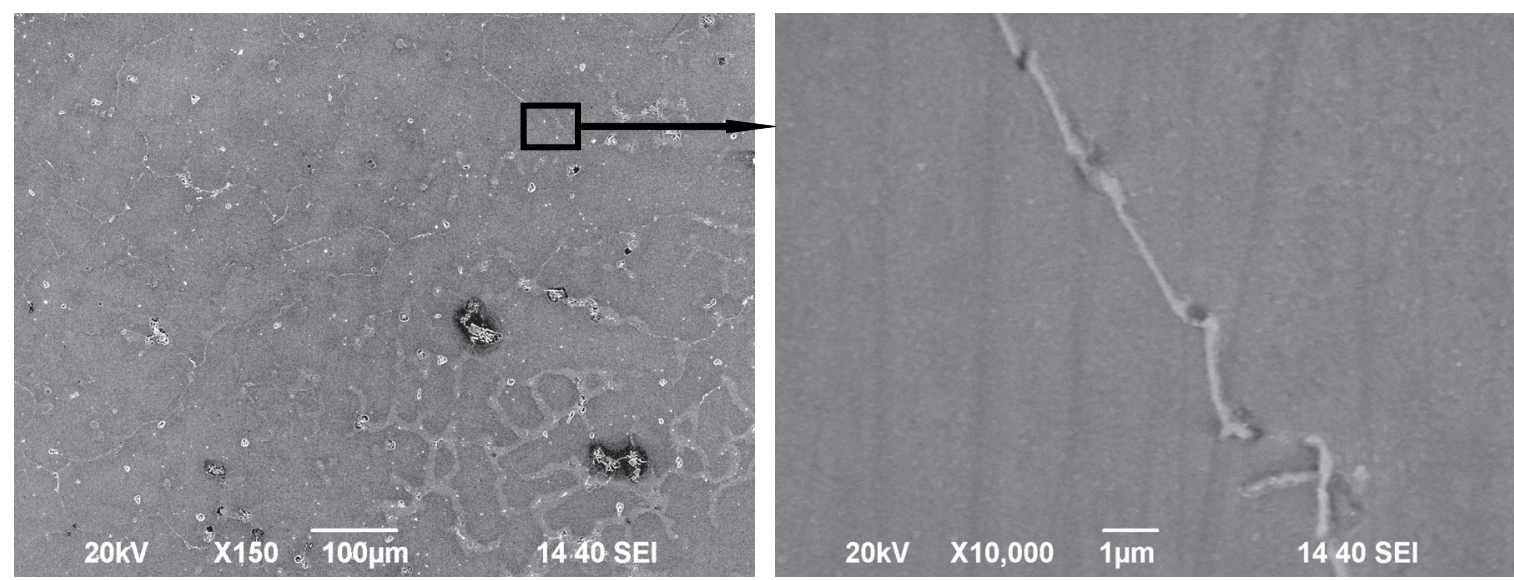

Fig. 9: Microstructure of Hadfield steel cooled in the temperature range of excessive phase separation with the cooling rate of $1.0^{\circ} \mathrm{C} \cdot \mathrm{s}^{-1}$

When the cooling rate is $1.8^{\circ} \mathrm{C} \cdot \mathrm{s}^{-1}$, the thickness of the excessive phase further decreases to about $0.1-0.3 \mu \mathrm{m}$, while the Fe/Mn ratio reaches the value of 5.7-5.8. Phosphide eutectic changes its morphology dramatically (Fig. 10). It is separated in the form of round inclusions of up to $5 \mu \mathrm{m}$ in size with phosphor content of $4.7 \%-6.3 \%$. At such cooling rates, no eutectic with lamellar morphology is found in the structure. The content of alloying elements in austenite decreases: for manganese to $10.3 \%$; for chrome to $0.8 \%$; for silicon to $0.7 \%$.

Further increase of the cooling rate by three times, to the value 


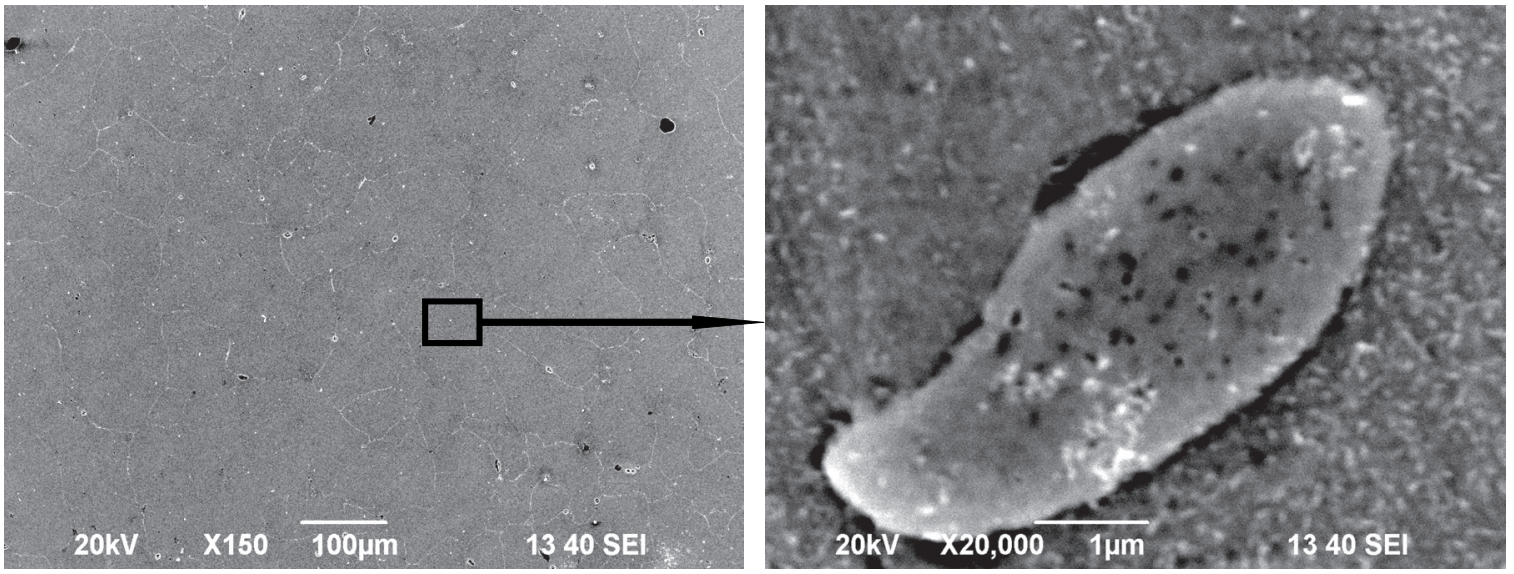

Fig. 10: Microstructure of Hadfield steel cooled in the temperature range of excessive phase separation with the cooling rate of $1.8^{\circ} \mathrm{C} \cdot \mathrm{s}^{-1}$

of $5.46{ }^{\circ} \mathrm{C} \cdot \mathrm{s}^{-1}$, results in thickness reduction of the excessive phase to about $0.05-0.2 \mu \mathrm{m}$ (Fig. 11). The manganese content in it decreases, which is why the ratio of $\mathrm{Fe} / \mathrm{Mn}$ equals 6.3. The size of rounded inclusions of phosphide eutectic decreases to $2 \mu \mathrm{m}$. At such high cooling rates, partial disintegration of the carbide net separated along the grain boundaries takes place as it disintegrates into a number of separate, highly dispersed inclusions. Manganese content in the chemical composition decreases to $8.2 \%$, chrome and silicon contents do not change at $0.8 \%$ and $0.7 \%$, respectively.
Beside the excessive phase, martensite can be present in the as-cast structure of Hadfield steel. It is formed in the structure of samples cooled in the temperature range of excessive phase precipitation with a cooling rate of $0.24{ }^{\circ} \mathrm{C} \cdot \mathrm{s}^{-1}$ or lower. This is confirmed by both metallographic examination [Fig. 6(b, c)] and $\mathrm{X}$-ray crystal structure analysis. The X-ray diffraction pattern of such a specimen shows the characteristic maximum of martensite (Fig. 12a). When the cooling rate of the casting increases to $0.35{ }^{\circ} \mathrm{C} \cdot \mathrm{s}^{-1}$, no martensite is present in its structure. This fact is confirmed by the absence of the characteristic maximum in the X-ray diffraction pattern (Fig. 12b).
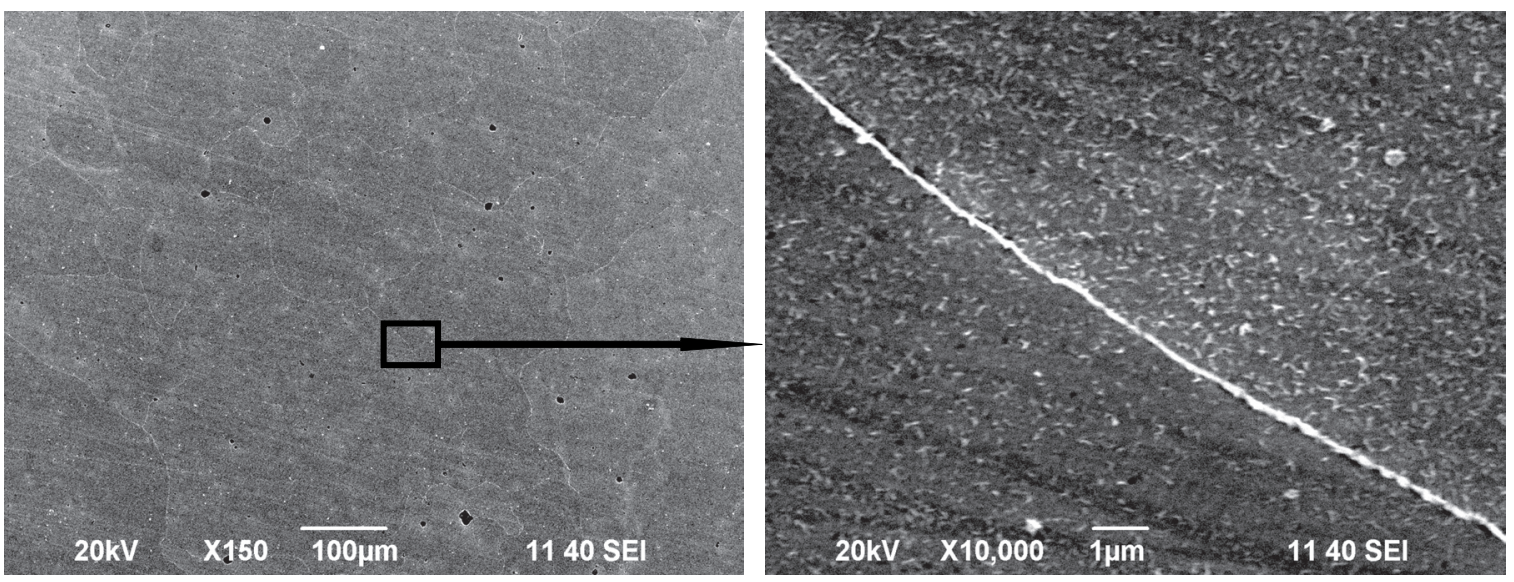

Fig. 11: Microstructure of Hadfield steel cooled in the temperature range of excessive phase separation with the cooling rate of $5.46^{\circ} \mathrm{C} \cdot \mathrm{s}^{-1}$
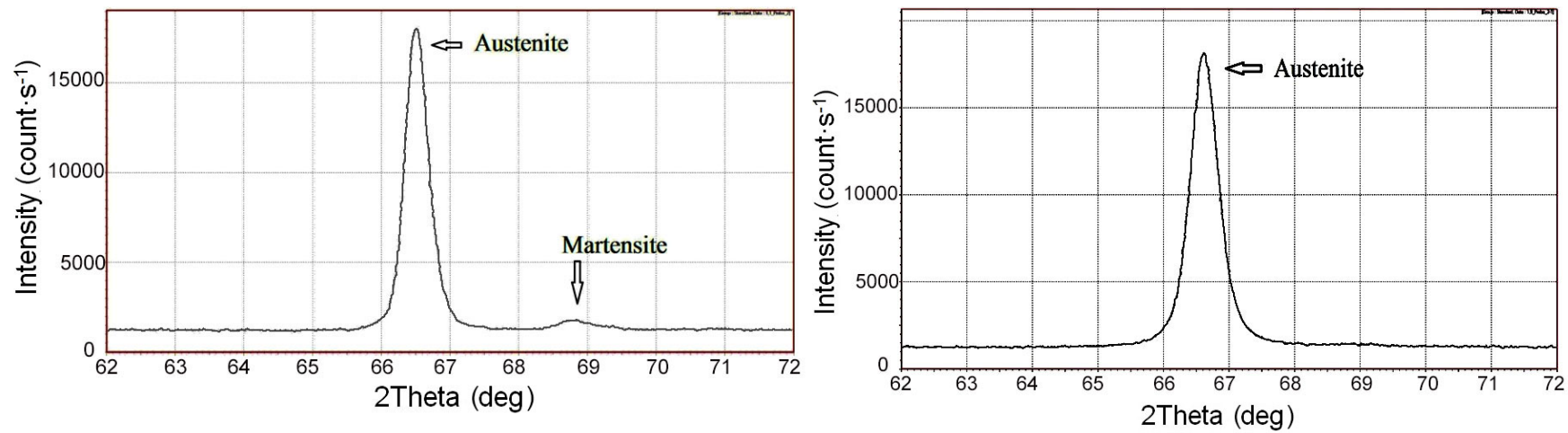

Fig. 12: X-ray diffraction pattern of the as-cast Hadfield steel cooled with the cooling rates: $a-0.24{ }^{\circ} \mathrm{C} \cdot \mathrm{s}^{-1} ; \mathrm{b}-0.35^{\circ} \mathrm{C} \cdot \mathrm{s}^{-1}$ 


\subsection{Mechanisms of stress state forming in a casting}

Alloy transitioning from the liquid state to the solid and further cooling results in forming the first class residual stresses in a casting. These are caused by the combined action of several kinds of stresses: shrinkage, thermal and phase stresses.

The value of shrinkage stresses depends on the cooling rate of the casting in the temperature range of crystallization. Phase stresses depend on the changes in the number of secondary phases, in this case, on the cooling rate of the casting in the temperature range of the excessive phase separation (Fig. 5). Thermal stresses result from the temperature gradient along the casting cross-section. Within the framework of the present research work, the influence of thermal stresses was not taken into account because of two reasons. The first reason is that the research work was carried out using small specimens, which are thermally thin bodies, and, consequently, there is no significant temperature difference along their cross-sections. The second reason is that thermal stresses depend mostly on geometry, and are unique for each particular product. They are not referred to as residual stresses and are completely relieved after temperature homogenization along the body of the casting (for example, after complete cooling to room temperature).

That is why it is quite natural that the change of the cooling rate in the temperature range of crystallization, and the excessive phase separation will result in forming of different residual stresses of the first class (different by the sign and by the value).

LWMFlow software was used to simulate the crystallization process of the specimens under study and to calculate the theoretical values of shrinkage stresses for different cooling rates. In accordance with the obtained data (Fig. 13a), it was found that tensile shrinkage stresses are formed when the cooling rate of the casting in the temperature range of crystallization is lower than $16^{\circ} \mathrm{C} \cdot \mathrm{s}^{-1}$. The increase of the cooling rate above this value up to $250{ }^{\circ} \mathrm{C} \cdot \mathrm{s}^{-1}$ does not result in any change of the value of the shrinkage stresses and remains equal to $0 \mathrm{MPa}$.

$\mathrm{X}$-ray crystal structure analysis was used to determine residual stresses of the first class in the castings at the room temperature (Fig. 13b). This relationship shows that if the cooling rate of the casting in the temperature range of crystallization is $12{ }^{\circ} \mathrm{C} \cdot \mathrm{s}^{-1}$ (in the temperature range of excessive phase separation, it is 2.6 ${ }^{\circ} \mathrm{C} \cdot \mathrm{s}^{-1}$ ), residual stresses in the casting change qualitatively from tensile to compressive ones.

Taking into account that residual stresses are the sum of shrinkage and phase stresses, one can calculate the values of phase stresses depending on the cooling rate of the casting in the temperature range of excessive phase separation (Fig. 14).

The obtained data show that the increase in the cooling rate
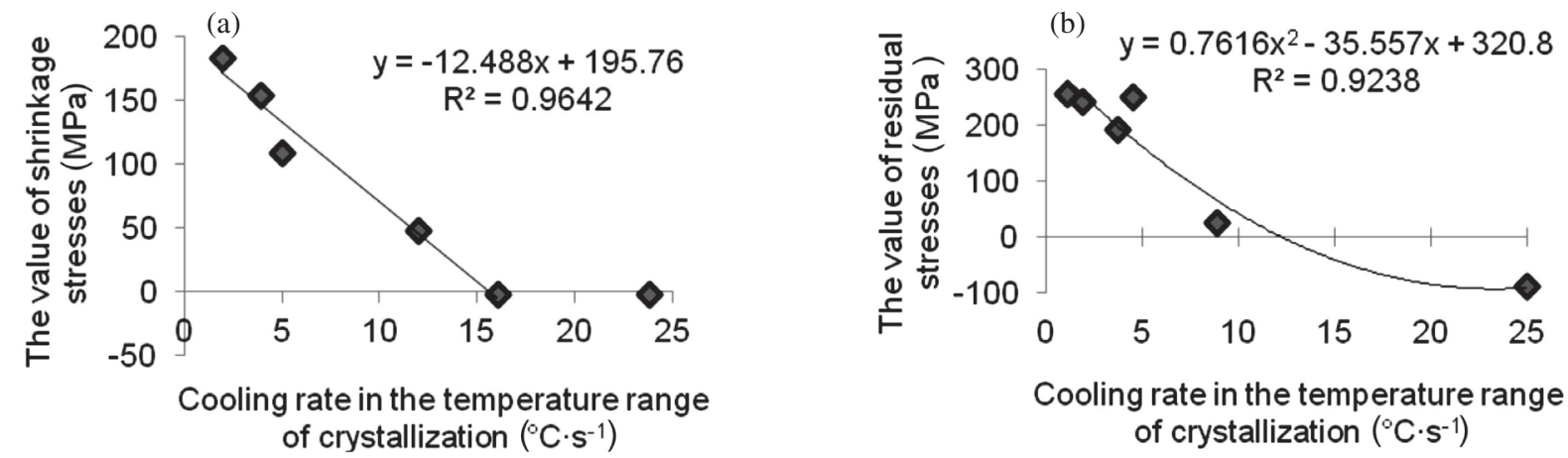

Fig. 13: Relationship between the value of stresses and the cooling rate of the casting in the temperature range of crystallization: $a$ - shrinkage stresses; $b$ - residual stresses of the first class

results in the steady decrease in the value of tensile stresses. If the cooling rate is $1.3{ }^{\circ} \mathrm{C} \cdot \mathrm{s}^{-1}$, the value of stresses is $0 \mathrm{MPa}$, and a further increase in the cooling rate results in the development of compressive stresses in the casting. At the same time, their value is proportional to the cooling rate in the temperature range of excessive phase separation.

\section{Discussion}

The research work showed that the as-cast Hadfield steel structure is formed mainly in two temperature ranges: the temperature ranges of crystallization and excessive phase separation. The critical role influencing the qualitative and quantitative characteristics of the microstructure is played by the

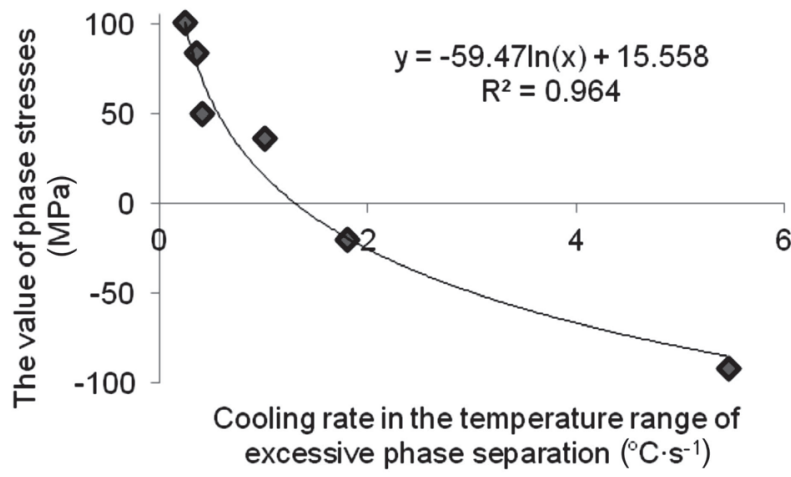

Fig. 14: Relationship between the value of phase stresses and the cooling rate in the temperature range of excessive phase separation 
cooling rates of the casting in these temperature ranges.

The cooling rate in the temperature range of crystallization influences the size of austenite grain, homogeneity of grain size of the as-cast structure and the values of shrinkage stresses in the casting.

Low cooling rate of an alloy contributes to formation of a few centers of crystallization. The process of transition to the ordered state occurs through the growth of these few nuclei of the solid phase. The increase of the cooling rate contributes to the increase of the degree of supercooling, and, consequently, the difference in the free energy between the solid and liquid states increases. This results in formation of numerous nuclei of critical size and formation of fine-grained structure. The twentyfold difference in the cooling rates during crystallization results in grain reduction of the average austenite grain from 266 $\mu \mathrm{m}$ (at the cooling rate of $1.1{ }^{\circ} \mathrm{C} \cdot \mathrm{s}^{-1}$ ) to $131 \mu \mathrm{m}$ (at the cooling rate of $\left.25.0^{\circ} \mathrm{C} \cdot \mathrm{s}^{-1}\right)$. The most uniform structure is formed at the cooling rate of $8.9^{\circ} \mathrm{C} \cdot \mathrm{s}^{-1}$. This value of the cooling rate makes it possible to achieve a certain balance between the rate of grain growth and the rate of grain nucleation. The decrease of the cooling rate results in the selective growth of individual grains. The increase of the cooling rate results in the slowdown of individual grain growth due to the hindered diffusion.

At low cooling rates, the transition of the casting from the liquid to the solid state is accompanied by the development of tensile shrinkage stresses in its body, which turn into residual stresses after complete cooling. This is the result of low movement of the crystallization front and the difference in volumes of the same mass of metal in the solid and liquid states. When the shrinkage stresses reach the values which are equal to or even higher than the values of the breaking stress, the integrity of the casting is broken, resulting in discontinuities and porosity. Gradual increase of the cooling rate results in the steady decrease of the values of tensile shrinkage stresses. When the cooling rate is $16.0{ }^{\circ} \mathrm{C} \cdot \mathrm{s}^{-1}$ or higher, the process of crystallization develops without any shrinkage stresses. This results from faster advancement of the crystallization front and the minimum time of the alloy being in the two-phase region.

The second temperature range influencing the forming of the cast structure of Hadfield steel is the temperature range of the excessive phase separation. Change of the cooling rate influences the number of phases, their morphology and chemical composition, as well as the possibility of martensite forming and the development of phase stresses.

When the cooling rate increases, the amount of excessive phase decreases steadily. When the cooling rate is $0.25^{\circ} \mathrm{C} \cdot \mathrm{s}^{-1}$, about $15.0 \%$ of this constituent is separated in the structure. At the same time, alloying of austenite decreases, especially in small regions surrounded by a large amount of the secondary phase. This austenite has low resistance to breakdown and during further cooling, it partially transforms to martensite. When the cooling rate is $5.5^{\circ} \mathrm{C} \cdot \mathrm{s}^{-1}$, its amount is $2.0 \%$. This contributes to the preserving of austenite alloying and its resistivity to breakdown. That is why when the cooling rate is $0.35^{\circ} \mathrm{C} \cdot \mathrm{s}^{-1}$, no martensite is formed in the structure.
At low cooling rates (lower than $0.25{ }^{\circ} \mathrm{C} \cdot \mathrm{s}^{-1}$ ), the excessive phase is represented totally by phosphide thin-lamellar eutectic with high manganese content. The increase of the cooling rate results in the change of the excessive phase morphology. Due to hindered diffusion of phosphorus, the separated fragments of lamellar eutectic continue their growth in the form of columnwise carbides. This also influences their chemical composition: manganese content decreases.

If the cooling rate of the alloy is within the range of $0.35-1.0$ ${ }^{\circ} \mathrm{C} \cdot \mathrm{s}^{-1}$, the excessive phase is composed of both eutectic with the gradually decreasing degree of dispersion and of carbides. The quantitative ratio changes gradually in favor of carbides with the pronounced difference in thickness from 0.2 to 0.4 $\mu \mathrm{m}$. The increase of the cooling rate to $1.8^{\circ} \mathrm{C} \cdot \mathrm{s}^{-1}$ changes the morphology of the excessive phase. The eutectic does not have a coherent boundary with carbides and is separated in the form of individual rounded inclusions of $5 \mu \mathrm{m}$ in size. The carbides are separated in the form of a continuous net with a more uniform thickness from 0.1 to $0.3 \mu \mathrm{m}$. Further increase in the cooling rate (over $5.0^{\circ} \mathrm{C} \cdot \mathrm{s}^{-1}$ ) results in the decrease of the round eutectic inclusions to $2 \mu \mathrm{m}$. Hindering of diffusion processes causes partial destruction of the integrity of the carbide net. Increase of the cooling rate from 0.35 to $5.46^{\circ} \mathrm{C} \cdot \mathrm{s}^{-1}$ results in the decrease of alloying of the excessive phase with manganese, that is why the $\mathrm{Fe} / \mathrm{Mn}$ ratio increases from 3.5 to 6.3 , while the total content of manganese in the structure goes down from $6.7 \%$ to $2.1 \%$. That is why it is quite natural that austenite contains more alloying elements.

The result of changes in the quantitative ratio between the excessive phase and austenite and its alloying is the formation of phase stresses in a casting.

Decreasing the amount of the excessive phase from $15 \%$ to $4 \%$ results in the change of the value of the forming tensile stresses from +100 to $0 \mathrm{MPa}$. If the amount of the excessive phase in the structure is less than $4 \%$, then the stresses formed are the compressive ones. If the amount of the excessive phase separated in the structure is $2 \%$, the compressive stresses increase to $-100 \mathrm{MPa}$. The reason is: in the high content of manganese in austenite, its solubility decreases while the deformation of the crystal lattice increases at cooling below the temperature of the excessive phase separation.

\section{Conclusions}

(1) The as-cast structure of Hadfield steel is formed primarily in two temperature ranges: the temperature range of crystallization $1,390-1,200{ }^{\circ} \mathrm{C}$; the temperature range of excessive phase separation $560-790^{\circ} \mathrm{C}$.

(2) The size of austenite grain has a power law dependence on the cooling rate of a casting in the temperature range of crystallization. It changes from 270 to $130 \mu \mathrm{m}$ when the cooling rate increases from 1.1 to $25.0{ }^{\circ} \mathrm{C} \cdot \mathrm{s}^{-1}$. The most uniform structure is formed when the cooling rate is $8.9^{\circ} \mathrm{C} \cdot \mathrm{s}^{-1}$.

(3) The amount of the excessive phase has a power law dependence on the cooling rate in the temperature range of its 
separation. Its amount decreases from $14.8 \%$ to $2.1 \%$ when the cooling rate increases from 0.24 to $5.5{ }^{\circ} \mathrm{C} \cdot \mathrm{s}^{-1}$. Excessive phase can be composed of two structural components: eutectic and carbides. When the cooling rate changes, their quantitative ratio and morphology also change.

(4) When the cooling rate of the alloy in the temperature range of excessive phase separation is lower than $0.35{ }^{\circ} \mathrm{C} \cdot \mathrm{s}^{-1}$, the degree of alloying of austenite decreases and its partial transformation into austenite occurs.

(5) Changes in the cooling rate of a casting during and after crystallization result in forming of different stresses of the first class, which are the sum of shrinkage and phase stresses. Shrinkage stresses have an inverse relationship with the cooling rate during crystallization. When the value of the cooling rate is $\geqslant 16{ }^{\circ} \mathrm{C} \cdot \mathrm{s}^{-1}$, no shrinkage stresses are formed. The value of phase stresses is influenced by the cooling rate in the temperature range of the excessive phase separation (logarithmic relationship). When the cooling rate increases from 0.24 to 1.3 ${ }^{\circ} \mathrm{C} \cdot \mathrm{s}^{-1}$, the value of phase stresses decreases from +100 to 0 $\mathrm{MPa}$. Further increase of the cooling rate from 1.3 to $5.5^{\circ} \mathrm{C} \cdot \mathrm{s}^{-1}$ changes the value of stresses from 0 to $-100 \mathrm{MPa}$.

\section{References}

[1] Curiel-Reyna E, Contreras J, Rangel-Ortis T, et al. Effect of Carbide Precipitation on the Structure and Hardness in the Heat-Affected Zone of Hadfield Steel After Post-Cooling Treatments. Materials and Manufacturing Processes, 2007, 23(1): 14-20.

[2] Owen W S, Grujicic M. Strain aging of austenitic Hadfield manganese steel. Acta Materialia, 1998, (47)1: 111-126.

[3] Adler P H, Olson G B, Owen W S. Strain Hardening of Hadfield Manganese Steel. Metallurgical and Materials Transactions A, 1986, 17(10): 1725-1737.

[4] Dastur Y N, Leslie W C. Mechanism of work hardening in Hadfield manganese steel. Metallurgical Transactions A, 1981, 12(5): 749-759.

[5] Bouaziz O, Allain S, Scott C P, et al. High manganese austenitic twinning induced plasticity steels: A review of the microstructure properties relationships. Current Opinion in Solid State and Materials Science, 2011, 15(4): 141-168.

[6] Yan Weilin, Fang Liang, Zheng Zhanguang, et al. Effect of surface nanocrystallization on abrasive wear properties in Hadfield steel. Tribology International, 2009, 42(5): 634-641.

[7] Yan Weilin, Fang Liang, Sun Kun, et al. Thermodynamics of nanocrystilline formation in surface layer of Hadfield steel by shot peening. Materials Science and Engineering A, 2007, 445-446(6): 392-397.

[8] Yan Weilin, Fang Liang, Sun Kun, et al. Effect of surface work hardening on wear behavior of Hadfield steel. Materials Science and Engineering A, 2007, 460-461(4): 542-549.

[9] Zhang F C, Yang Z N, Qian L H, et al. High speed pounding: A novel technique for the preparation of a thick surface layer with a hardness gradient distribution on Hadfield steel. Scripta Materialia, 2011, 64(6): 560-563.

[10] Canadinc D, Sehitoglu H, Maier H J. The role of dense dislocation walls on the deformation response of aluminum alloyed hadfield steel polycrystals. Materials Science and Engineering A, 2007, 454-455(16): 662-666.

[11] Iglesias C, Solórzano G, Schulz B. Effect of low nitrogen content on work hardening and microstructural evolution in Hadfield steel. Materials Characterization, 2009, 60(9): 971979.

[12] Wen $Y H$, Peng $H$ B, Si H T, et al. A novel high manganese austenitic steel with higher work hardening capacity and much lower impact deformation than Hadfield manganese steel. Materials and Design, 55(6): 798-804.

[13] Xiong Renlong, Peng Huabei, Wang Shanling, et al. Effect of stacking fault energy on work hardening behaviors in Fe-MnSi-C high manganese steels by varying silicon and carbon contents. Materials and Design, 2015, 85: 707-714.

[14] Abbasi Majid, Kheirandish Shahram, Kharrazi Yosef, et al. The fracture and plastic deformation of aluminum alloyed Hadfield steels. Materials Science and Engineering A, 2009, 513-514(11): 72-76.

[15] Ali Nasajpour, AmirHossein Kokabi, Parviz Davami, et al. Effect of molybdenum on mechanical and abrasive wear properties of coating of as-weld hadfield steel with flux-cored gas tungsten arc welding. Journal of Alloys and Compounds, 2016, 659: 262-269.

[16] Jiang Qichuan, He Zhenming, Cui Donghuan, et al. Abrasionresistant as-cast manganese steel with nodular carbide modified by calcium. Journal of Materials Science Letters, 1990, 9(5): 616-617.

[17] Zuidema B K, Subramanyam D K, Leslie W C. The Effect of Aluminum on the Work Hardening and Wear Resistance of Hadfield Manganese Steel. Metallurgical and Materials Transactions A, 1987, 18(9): 1629-1639.

[18] Dastur Y N, Leslie W C. Mechanism of Work Hardening in Hadfield Manganese Steel. Metallurgical Transactions A, 1981, 12(5): 749-759.

[19] Radis R, Schlacher C, Kozeschnik E, et al. Loss of Ductility Caused by AIN Precipitation in Hadfield Steel. Metallurgical and Materials Transactions A, 2012, 43(4): 1132-1139.

[20] LÜ B, Zhang F C, Li M, et al. Effects of phosphorus and sulfur on the thermoplasticity of high manganese austenitic steel. Materials Science and Engineering A, 2010, 527(21-22): 5648-5653.

[21] Vdovin K N, Feoktistov N A, Sinitskii E V, et al. Production of high-manganese steel in arc furnaces: Part 1. Steel in Translation, 2015, 45(10): 729-732.

[22] Xiong Renlong, Peng Huabei, Si Haitao, et al. Thermodynamic calculation of stacking fault energy of the Fe-Mn-Si-C high manganese steels. Materials Science and Engineering A, 2014, 598: 376-386.

[23] Karaman I, Sehitoglu H, Chumlyakov Y I, et al. Extrinsic stacking faults and twinning in Hadfield manganese steel single crystals. Scripta Materialia, 2001, 44(2): 337-343.

[24] Astafurova E G, Tukeeva M S, Maier G G, et al. Microstructure and mechanical response of single-crystalline high-manganese austenitic steels under high-pressure torsion: The effect of stacking-fault energy. Materials Science and Engineering A, 2014, 604: 166-175.

[25] Astafurova E G, Tukeeva M S, Zakharova G G, et al. The role of twinning on microstructure and mechanical response of severely deformed single crystals of high-manganese austenitic steel. Materials Characterization, 2011, 62(6): 588592.

[26] Efstathiou C, Sehitoglu H. Strain hardening and heterogeneous deformation during twinning in Hadfield steel. Acta Materialia, 2010, 58(5): 1479-1488.

[27] Idrissi H, Renard K, Ryelandt L, et al. On the mechanism of twin formation in Fe-Mn-C TWIP steels. Acta Materialia, 2010, 58(7): 2464-2476.

[28] Karaman I, Sehitoglu H, Gall K, et al. Deformation of single 
crystal hadfield steel by twinning and slip. Acta Materialia, 2000, 48(6): 1345-1359.

[29] Hutchinson B, Ridley N. On dislocation accumulation and work hardening in Hadfield steel. Scripta Materialia, 2006, 55(4): 299-302.

[30] Zhang Wanhu, Wu Junliang, Wen Yuhua, et al. Characterization of different work hardening behavior in AISI 321 stainless steel and Hadfield steel. Journal of Materials Science, 2010, 45(13): 3433-3437.

[31] Ueji R, Kondo D, Takagi Y, et al. Grain size effect on highspeed deformation of Hadfield steel. Journal of Materials Science, 2012, 47(22): 7946-7953.

[32] Lindroos M, Apostol M, Heino V, et al. The Deformation, Strain Hardening, and Wear Behavior of Chromium-Alloyed Hadfield Steel in Abrasive and Impact Conditions. Tribology Letters, 2015, 57(3):1-11

[33] Feng Xiaoyong, Zhang Fucheng, Zheng Chunlei, et al. Micromechanics behavior of fatigue cracks in Hadfield steel railway crossing. Science China Technological Sciences, 2013, 56(5): 1151-1154.

[34] Saeed- Akbari A, Imlau J, Prahl U, et al. Derivation and Variation in Composition-Dependent Stacking Fault Energy Maps Based on Subregular Solution Model in High-Manganese Steels. Metallurgical and Materials Transactions A, 2009, 40(13): 3076-3090.

[35] Jost N, Schmidt I. Friction-induced martensitic transformation in austenitic manganese steels. Wear, 1986, 111(4): 377-389.
[36] Rittel D, Roman I. Tensile deformation of coarse-grained cast austenitic manganese steels. Metallurgical and Materials Transactions A, 1988,19(9): 2269-2277.

[37] Srivastava A K, Das K. Microstructural characterization of Hadfield austenitic manganese steel. Journal of Materials Science, 2008, 43(16): 5654-5658.

[38] Tian Xing, Li Hong, Zhang Yansheng. Effect of Al content on stacking fault energy in austenitic Fe-Mn-Al-C alloys. Journal of Materials Science, 2008, 43(8): 6214-6222.

[39] Niu Libin, Hojamberdiev Mirabbos, Xu Yunhua, et al. Microstructure and mechanical properties of Hadfield steel matrix composite reinforced with oriented high-chromium cast iron bars. Journal of Materials Science, 2010, 45(16): 45324538.

[40] Chen Liqing, Zhao Yang, Qin Xiaomei. Some aspects of high manganese twinning- induced plasticity (TWIP) steel, a review. Acta Metallurgica Sinica (English Letters), 2013, 26(1): 1-15.

[41] El-Fawkhry M K, Fathy A M, Eissa M M, et al. Eliminating Heat Treatment of Hadfield Steel in Stress Abrasion Wear Applications. International Journal of Metalcasting, 2014, 8(1): 29-36.

[42] Koptseva N V, Chukin M V, Nikitenko O A. Use of the Thixomet PRO software for quantitative analysis of the ultrafine-grain structure of low-and medium-carbon steels subjected to equal channel angular pressing. Metal Science and Heat Treatment, 2012, 54(7): 